\title{
Práticas de atenção ao parto na experiência de puérperas: análise à luz da humanização
}

Delivery care practices in the experience of puerperal women: analysis in the light of humanization

Prácticas de atención de parto en la experiencia de las mujeres puerperales: análisis a la luz de la humanización

\section{Pâmela da Rosa Gonzalez ${ }^{\text {I }}$ Lisie Alende Prates ${ }^{\text {II }}$, Joice Moreira Schmalfuss ${ }^{\text {III }}$, Jussara Mendes Lipinski $^{\mathrm{IV}}$, Ana Paula de Lima Escobalv ${ }^{\mathrm{V}}$, Mari Luci Chalme da Silva ${ }^{\mathrm{VI}}$}

\begin{abstract}
Resumo: Objetivo: analisar as experiências de puérperas acerca das práticas profissionais desenvolvidas na atenção ao parto à luz do aporte teórico da humanização. Método: pesquisa qualitativa, com a participação de dez puérperas que vivenciaram parto vaginal, por meio de entrevista semiestruturada, desenvolvida entre setembro e novembro de 2019 . Adotou-se a análise temática. Resultados: predominaram práticas que se distanciaram da humanização, como enema, restrição hídrica e alimentar, exames vaginais frequentes, episiotomia, manobras de Valsalva e de Kristeller. As práticas que se aproximaram da humanização foram a presença do acompanhante, utilização de métodos de alívio da dor no parto e contato cutâneo precoce entre mãe e bebê. Conclusão: as experiências das puérperas foram marcadas, principalmente, por condutas profissionais prejudiciais ou ineficazes, realizadas de forma inadequada e com poucas evidências científicas sobre a sua eficácia. Espera-se subsidiar a reflexão quanto à necessidade de revisão e atualização quanto às boas práticas de atenção ao parto.
\end{abstract}

Descritores: Enfermagem; Saúde da mulher; Parto; Parto humanizado; Humanização da assistência

\footnotetext{
${ }^{\text {I }}$ Acadêmica de Enfermagem, Universidade Federal do Pampa, Uruguaiana, RS, Brasil. E-mail: pame.gonz@hotmail.com, Orcid: http://orcid.org/00000003-1961-4398.

II Enfermeira, Doutora em Enfermagem, Universidade Federal do Pampa/Professora Adjunta, Uruguaiana, RS, Brasil. E-mail: lisiaealende@hotmail.com, Orcid: http://orcid.org/0000-0002-5151-0292.

III Enfermeira, Doutoranda em Ciências da Saúde, Universidade Federal da Fronteira Sul/Professora Assistente, Chapecó, SC, Brasil. E-mail: joicemschmalfuss@gmail.com, Orcid: http://orcid.org/0000-0002-0293-9957.

IV Enfermeira, Doutora em Enfermagem, Universidade Federal do Pampa/Professora Titular, Uruguaiana, RS, Brasil. E-mail: jussaralipinski@gmail.com, Orcid: http://orcid.org/0000-0002-3907-0722.

V Enfermeira, Doutora em Enfermagem, Universidade Federal do Pampa/Professora Adjunta, Uruguaiana, RS, Brasil. E-mail: anapaulaescobal@hotmail.com, Orcid: http://orcid.org/0000-0002-2601-9098.
}

VI Acadêmica de Enfermagem, Universidade Federal do Pampa, Uruguaiana, RS, Brasil. E-mail: mari.chalme02@gmail.com, Orcid: http://orcid.org/00000002-7632-0751. 
Práticas de atenção ao parto na experiência de puérperas: análise à luz da humanização $\mid 2$

\begin{abstract}
Objective: to analyze the experiences of puerperal women about the professional practices developed in delivery care in the light of the theoretical contribution of humanization. Method: qualitative research, with the participation of ten puerperal women who experienced vaginal delivery, through semi-structured interviews, developed between September and November 2019. Thematic analysis was adopted. Results: practices that distanced themselves from humanization, such as enema, water and food restriction, frequent vaginal examinations, episiotomy, Valsalva and Kristeller maneuvers, predominated. The practices that approached humanization were the presence of the companion, use of methods of pain relief in the delivery and early skin contact between mother and baby. Conclusion: the experiences of the puerperal women were mainly marked by harmful or ineffective professional behaviors, performed inappropriately and with little scientific evidence about their efficacy. It is expected to support the reflection on the need for review and updating regarding good practices of delivery care.
\end{abstract}

Descriptors: Nursing; Women's health; Parturition; Humanizing delivery; Humanization of assistance

Resumen: Objetivo: analizar las experiencias de las mujeres puerperales sobre las prácticas profesionales desarrolladas en la atención del parto a la luz de la contribución teórica de la humanización. Método: investigación cualitativa, con la participación de diez mujeres puerperales que experimentaron el parto vaginal, a través de entrevistas semiestructuradas, desarrolladas entre septiembre y noviembre de 2019. Se adoptó un análisis temático. Resultados: predominaron las prácticas que se distanciaron de la humanización, como el enema, la restricción del agua y los alimentos, los exámenes vaginales frecuentes, la episiotomía, las maniobras de Valsalva y Kristeller. Las prácticas que se acercaron a la humanización fueron la presencia del compañero, el uso de métodos de alivio del dolor en el parto y el contacto temprano de la piel entre la madre y el bebé. Conclusión: las experiencias de las mujeres puerperales estuvieron marcadas principalmente por conductas profesionales dañinas o ineficaces, realizadas de manera inapropiada y con poca evidencia científica sobre su eficacia. Se espera que apoye la reflexión sobre la necesidad de revisar y actualizar las buenas prácticas de la atención al parto.

Descriptores: Enfermería; Salud de la mujer; Parto; Parto humanizado; Humanización de la atención

\title{
Introdução
}

Nas últimas décadas, tem-se observado mudanças nos determinantes sociais e na organização dos serviços de saúde no Brasil. Na atenção ao parto e nascimento, essas modificações têm sido permitidas por meio da implementação de políticas e programas, como é o caso da Rede Cegonha, a qual propôs, dentre outras ações, a adoção de práticas baseadas em evidências científicas. Contudo, ainda persistem desafios substanciais, especialmente porque há baixa adesão dos profissionais de saúde às estratégias que poderiam modificar o modelo obstétrico vigente, tais como as boas práticas de atenção ao parto e nascimento. ${ }^{1-2}$

Tratando-se dessas práticas, cabe mencionar que elas foram recomendadas pela Organização Mundial da Saúde (OMS), no ano de 1996, com o objetivo de conduzir o trabalho dos profissionais 
atuantes na área obstétrica. Nesse sentido, foi proposta a classificação das práticas de atenção ao parto normal, em quatro categorias segundo facilidade, eficiência e risco, ${ }^{3}$ a qual foi adotada na análise do estudo em tela. A categoria A trata das práticas demonstrativamente úteis e que devem ser estimuladas; já a categoria B considera as condutas claramente prejudiciais ou ineficazes e que devem ser evitadas; a categoria C, por sua vez, abrange procedimentos com poucas evidências e que devem ser utilizados com cautela; e, enfim, a categoria D lista ações profissionais que, frequentemente, são utilizadas de modo inadequado. ${ }^{3}$

Apesar das tentativas nacionais e internacionais de propor um novo modo de atenção ao parto e ao nascimento, o modelo de intervenção hegemônico centrado na fragmentação e na verticalização das ações profissionais permanece enraizado nas instituições de saúde, especialmente no ambiente hospitalar. Constata-se que prevalece, ainda, a cultura de medicalização da atenção obstétrica, fazendo com que sejam impostos procedimentos invasivos convenientes aos profissionais..$^{3-5}$

Especialmente no Brasil, observa-se um contexto de epidemia de cesáreas eletivas, com taxas cada vez mais crescentes, no qual a mulher, muitas vezes, é destituída do poder de decisão sobre o próprio corpo. ${ }^{5}$ Em contraponto a esse contexto, tem-se observado um movimento de rompimento com essa perspectiva hegemônica e em prol da adoção de práticas pautadas na humanização do parto e nascimento, ${ }^{4}$ tendo como referencial, por exemplo, as recomendações da OMS. ${ }^{3}$

A definição de humanização, adotada no presente estudo, está centrada na produção de novos modelos de cuidado e de organização do trabalho. ${ }^{6}$ No cenário de parturição e nascimento, a humanização abrange o respeito às escolhas da mulher, família e bebê, assim como o direito de atendimento digno e respeitoso, livre de qualquer tipo de violência. ${ }^{7-8}$ Nesse sentido, dentre os profissionais que atuam na atenção ao parto, os enfermeiros têm se destacado por seu engajamento e comprometimento com um cuidado humanizado pautado nas boas práticas. ${ }^{4,8}$ Contudo, é preciso que outros profissionais que assistem a parturiente também possam repensar o modelo obstétrico e, com isso, assumam as boas práticas como possibilidade de transformação do processo de parturição. 
Práticas de atenção ao parto na experiência de puérperas: análise à luz da humanização $\mid 4$

Considerando o panorama atual, em que, muitas vezes, procedimentos prejudiciais, ineficazes e com poucas evidências científicas estão presentes na práxis profissional, reconhece-se a importância de pesquisas que possam analisar as vivências de puérperas a partir das práticas profissionais na atenção ao parto. Sob essa perspectiva, o estudo destaca que as boas práticas podem colaborar em mudanças reais no contexto obstétrico. ${ }^{4}$

Mediante análise de produções na área, ${ }^{1-2,4-5,8}$ percebe-se que há uma lacuna de pesquisas a partir das vivências de puérperas acerca da implementação das boas práticas e/ou quanto às fragilidades existentes nesse processo, uma vez que os achados remetem às percepções dos profissionais de saúde. Desse modo, esse trabalho apresenta a seguinte questão de pesquisa: quais as experiências de puérperas acerca das práticas profissionais que se aproximam ou se distanciam da humanização na atenção ao parto? Frente ao exposto, objetivou-se analisar as experiências de puérperas acerca das práticas profissionais desenvolvidas na atenção ao parto à luz do aporte teórico da humanização.

\section{Método}

Trata-se de uma pesquisa exploratória e descritiva, com abordagem qualitativa, desenvolvida no sul do Brasil. A rede de atenção à saúde desse cenário dispõe de um hospital filantrópico, que atende 13 municípios da sua região, e 16 serviços de Estratégia Saúde da Família (ESF) localizados na região urbana. Nesses serviços, além dos atendimentos aos usuários, também são desenvolvidas atividades práticas e estágios curriculares de discentes dos cursos da área da saúde de uma instituição de ensino pública.

O contato com as participantes se deu em quatro das 16 ESF do município. Nesse sentido, vale destacar que houve sorteio de quatro ESF para a realização da pesquisa. A justificativa para realização desse procedimento concentrou-se no desejo de obter a percepção de puérperas residentes em localidades distintas, buscando uma maior variedade de experiências, uma vez que o 
fato de residir na mesma região poderia implicar na participação de mulheres com vivências e percepções muito similares à temática.

Para realização do sorteio, inicialmente as pesquisadoras realizaram uma divisão do mapa do município em quatro regiões. Neste mapa, havia a localização das 16 ESF e dentro da sua região, cada uma recebeu uma numeração de 1 a 4 . Na sequência, as pesquisadoras inseriram esse intervalo de números em formulário online e realizaram o sorteio individual de cada região, chegando, assim, à escolha dos serviços em que as participantes seriam localizadas.

Após, procedeu-se a identificação de participantes que atingiram os seguintes critérios de seleção: ser puérpera que teve parto vaginal no hospital do município e que estava vivenciando o puerpério tardio (entre o $11^{\circ}$ ao $42^{\circ}$ dia após o nascimento do bebê). ${ }^{9}$ Nesse sentido, destaca-se que o estudo teve como participantes dez puérperas. Portanto, vale ressaltar, por exemplo, que mulheres que tivessem apresentado perdas fetais ou com recém-nascidos hospitalizados também seriam incluídas, pois essas situações não prejudicariam a análise quanto à temática do estudo (práticas profissionais desenvolvidas na atenção ao parto à luz do aporte teórico da humanização). ${ }^{6}$ Contudo, essas situações não foram encontradas no grupo de participantes. Ainda, ressalta-se que não houve nenhuma recusa ou desistência ao longo da produção dos dados, sendo que se encerrou a captação de novas participantes quando atingido o critério de saturação de dados. ${ }^{10}$

Para isso, após a consulta puerperal realizada pelo enfermeiro, as mulheres foram abordadas pessoal e individualmente em cada uma das ESF sorteadas pelas acadêmicas participantes da equipe de pesquisa. O enfermeiro informava às acadêmicas sobre as puérperas que haviam vivenciado parto vaginal para que o convite pudesse ser realizado. Nesse momento, após apresentação do Termo de Consentimento Livre e Esclarecido, elas eram convidadas para participação na pesquisa.

Questionou-se o dia, horário e local mais apropriados. No que tange ao cenário, todas as puérperas optaram pelo seu próprio domicílio e a sala foi o local escolhido por elas para a realização da produção dos dados, os quais foram obtidos entre setembro e novembro de 2019, por meio de 
Práticas de atenção ao parto na experiência de puérperas: análise à luz da humanização 6

entrevista semiestruturada desenvolvida pelas duas acadêmicas que compuseram a equipe de pesquisa; as discentes foram capacitadas pela pesquisadora responsável. Todos os membros da equipe possuem experiência anterior com o uso da técnica de entrevista.

O roteiro de entrevista aberta foi elaborado para fins desta pesquisa e conteve dados de identificação pessoal e informações relacionadas às práticas profissionais adotadas no trabalho de parto e parto das mulheres. Durante a produção dos dados, solicitou-se que a participante relatasse o que havia ocorrido quando ela procurou a instituição hospitalar para o nascimento do seu bebê. Durante o depoimento da puérpera, alguns questionamentos foram realizados, no intuito de aprofundar a entrevista. Nesse sentido, ao longo da entrevista e de acordo com o que ia sendo exposto pela participante, alguns dos questionamentos levantados foram: Você teve algum acompanhante? Esta pessoa era quem você gostaria que te acompanhasse no parto e nascimento? Você entrou em trabalho de parto de forma espontânea ou foi necessária alguma medicação? Ofereceram-te algum líquido ou alimento durante o trabalho de parto? Depois que você chegou ao hospital, romperam a bolsa? Durante o trabalho de parto, o que você fazia? Foi feito enema (lavagem intestinal)? Foi feito tricotomia (raspagem de pelos da vagina)? Foi feito toque vaginal? Foi o mesmo profissional de saúde o que fez desde a sua chegada até o nascimento do bebê? Em algum momento, te pediram para fazer força? Quem, quando e por que te solicitaram isso? Na hora do parto, alguém apertou/subiu na sua barriga para ajudar o bebê a sair? Foi realizada episiotomia/corte/“pique”? Depois que o bebê nasceu, o que aconteceu?

As entrevistas tiveram uma duração estimada de 10 a 20 minutos, foram audiogravadas com smartphone e finalizadas quando todas as questões foram respondidas. Após, foram transcritas na íntegra por meio de digitação no processador de texto Microsoft Word. Os dados foram submetidos à análise temática, ${ }^{10}$ pautando-se como referencial teórico as evidências científicas para as boas práticas de atenção ao parto, conforme recomendações da OMS. ${ }^{3}$ A pesquisa respeitou as diretrizes e normas regulamentadoras das atividades de pesquisa envolvendo seres humanos, de acordo com a 
Resolução nº 466/2012. Antes da produção dos dados ser iniciada, o projeto foi aprovado pelo Comitê de Ética em Pesquisa, sob CAAE número 13460719.3.0000.5323 e processo número 3.535.870, em 27 de agosto de 2019. Para preservação do anonimato, foi empregado o sistema alfanumérico na apresentação dos depoimentos das puérperas, por meio da letra $\mathrm{P}$, acompanhada da numeração (P1, P2, P3...), simbolizando puérpera, considerando-se a ordem cronológica que as entrevistas aconteceram.

\section{Resultados}

As dez puérperas entrevistadas estavam na faixa etária entre 20 e 35 anos e encontravam-se entre o $11^{\circ}$ e o $42^{\circ}$ dia de pós-parto, e todas realizavam acompanhamento puerperal nas ESF. Dentre elas, cinco possuía ensino médio e nove união estável. Uma participante exercia trabalho doméstico e três desenvolviam trabalho fixo remunerado.

Todas residiam com os filhos e apenas uma não residia com o companheiro. Duas das participantes eram primíparas. Todas realizaram pré-natal, sendo que duas delas realizaram menos do que seis consultas durante o acompanhamento. Em relação ao planejamento e desejo em gestar, duas puérperas mencionaram que não planejaram nem desejaram a gravidez.

Mediante análise dos achados, estes foram organizados em duas categorias. A primeira foi denominada "Práticas que se aproximaram da humanização do parto" e a segunda "Práticas que se distanciaram da humanização do parto”.

\section{Práticas que se aproximaram da humanização do parto}

Muitas são as práticas com potencial para tranquilizar a mulher, durante o processo de parturição e nascimento. Uma dessas relaciona-se com a presença do acompanhante, de tal forma que promove segurança à mulher. Algumas entrevistadas afirmaram que um acompanhante de sua escolha esteve presente no período pré e/ou pós-parto.

A minha mãe foi a acompanhante da minha escolha. (P1) 
Práticas de atenção ao parto na experiência de puérperas: análise à luz da humanização $\mid 8$

Eu escolhi ficar com a minha cunhada. (P3)

No pré-parto e durante, eu só não tive porque minha mãe estava nervosa e daí não foi. Queria que fosse meu marido, mas ele não teve coragem [...] (P4)

Tive a mãe de acompanhante. (P8)

Minha irmã foi minha acompanhante. (P10)

Outras práticas que podem demonstrar benefícios à mulher dizem respeito à utilização de métodos não invasivos e não farmacológicos de alívio da dor durante o trabalho de parto e parto. Nesse sentido, a hidroterapia, a deambulação e os exercícios de relaxamento e agachamento foram mencionados como técnicas utilizadas durante o processo vivenciado pelas puérperas entrevistadas.

Ela [enfermeira] mandava ir mais vezes no banho para vir a dilatação [...] só não fui na bola, porque estava na dor do último e já não aguentava mais. Mas no banho fui, ficava bastante tempo no banho. (P4)

Só me mandaram [equipe de saúde] caminhar bastante. Caminhei bastante naquele corredor. (P6)

Me colocaram no banho e depois me colocaram a fazer um exercício para vir mais dor para ir mais rápido. Elas [equipe de enfermagem] falaram que tinha que se exercitar, para criança vir mais rápido. (P9)

Eu fazia os exercícios que tem lá na placa [era um quadro fornecido pelo Ministério da Saúde em que haviam imagens das posições que a parturiente pode adotar durante o trabalho de parto]. Me ajudou bastante. Era agachamento. Tomei até banho. Foi bem melhor. (P10)

O contato cutâneo direto e precoce entre mãe e filho fizeram parte da vivência de parturição de uma das participantes. Ela ainda citou o apoio para o início da amamentação na primeira hora após o parto.

Ela já saiu dali [da sala de parto] mamando. Depois que ganha ali, elas já colocam a bebê na teta. Não demoraram muito, foi o tempo de arrumar eu e ela. (P1)

Mediante esse último depoimento, vale destacar que apenas uma participante mencionou a prática de contato cutâneo direto e precoce com seu filho, imediatamente após o nascimento. 
Embora questionadas, as demais participantes não mencionaram essa vivência, ou seja, não lhe foi ofertada essa possibilidade.

\section{Práticas que se distanciaram da humanização do parto}

Considerando que as práticas que se distanciaram da humanização do parto são aquelas claramente prejudiciais ou ineficazes e que devem ser eliminadas nos serviços de saúde, algumas entrevistadas referiram terem sido submetidas a procedimentos rotineiros, como a tricotomia, salvo aquelas que já chegaram ao serviço com os pelos pubianos raspados por terem realizado tal procedimento em suas casas.

Não precisou raspar os pelos, isso eu faço em casa. (P2)

Não me depilaram, porque já tinha me depilado uns dias [...] a moça veio com esses aparelhos [...] ela viu e não precisou. (P7)

Também foi verificado que uma das participantes alegou que não teve a possibilidade de ter acompanhante. Segundo ela, em seu caso, ninguém foi autorizado a entrar/participar, durante o trabalho de parto e parto.

Fiquei sozinha, não deixaram. As minhas irmãs foram comigo, mas não deixaram entrar, fiquei sozinha. Lá na hora só ficou uma enfermeira comigo. (P9)

Outrossim, a cateterização venosa profilática e a infusão intravenosa de solução fisiológica e/ou de ocitocina exógena foram mencionadas por várias puérperas. Assim, evidenciou-se como prática rotineira e com a finalidade de apressar o trabalho de parto, parto e nascimento do bebê.

Eles [profissionais de saúde] me deram aquele soro para aumentar mais a dor. (P2)

Ela [enfermeira] colocou sorinho, estava com pouca dilatação, cinco dedos, aí coloquei soro e daqui um pouco estava com sete dedos, aí já me levaram para dentro e ganhei. (P5)

Ele [médico] colocou o soro e eu ganhei, em questão de minutos ganhei. (P6) 
Eles [profissionais de saúde] até colocaram acesso [venoso], mas foi natural mesmo. (P8)

A posição supina (decúbito dorsal) permanece sendo adotada durante o trabalho de parto. Em alguns casos, configurou-se como uma escolha (desinformada) da mulher e, em outros, partiu como uma restrição da equipe assistente.

Ficava só deitada, não conseguia caminhar [porque estava fazendo indução com ocitocina]. (P3)

Fiquei deitada só na cama, porque não dá para se levantar [porque estava fazendo indução com ocitocina]. (P7)

As entrevistadas também demonstraram que foram impedidas de ingerirem líquidos ou de se alimentarem durante o trabalho de parto. Algumas mencionaram que sentiram sede e fome e justificaram tal privação por orientações dos profissionais de saúde do serviço, sendo alegada a possibilidade de êmese, por exemplo.

[...] estava em trabalho de parto. Achei ruim porque dava sede, dava fome, dava tudo. (P2)

Não oferecem nada. Eu senti sede, só que não quis pedir. (P3)

[...] elas [equipe de enfermagem] não deixam. Não sei por que elas dizem que não é para tomar nada. Já estava com sede antes de ganhar ela, só que ela disse que eu não podia tomar água, e daí eu esperei. Eu pedi para tomar água e ela falou que agora não, era para esperar um pouquinho. (P8)

[...] não podia tomar água e nem comer nada. (P10)

As participantes relataram serem submetidas a exames vaginais repetidos ou de forma frequente, sendo que estes foram realizados por mais de um profissional de saúde. Uma delas mencionou, inclusive, que um profissional a machucou ao realizar tal procedimento.

Quando eu cheguei lá, primeiro foi um médico que fez toque, depois foi a doutora. (P2)

A enfermeira chefe e a médica faziam [o exame vaginal]. Às vezes, ela fazia e chamava a médica, aí a médica vinha e avaliava de novo. (P4) 
A doutora que fez [exame vaginal] [...] teve uma enfermeira chefe que fez também. (P5)

[...] o doutor fez, a doutora fez, outra enfermeira fez. (P6)

[...] as enfermeiras fizeram e a doutora depois antes de ir para sala, três pessoas fizeram. (P9)

Dois médicos fizeram toque e uma enfermeira. (P10)

As entrevistadas alegaram que foram estimuladas a realizar o esforço de puxo prolongado e dirigido (manobra de Valsalva), durante o trabalho de parto. Essa orientação foi transmitida por médicos e enfermeiros.

Ela [médica] só dizia que quando vinha a contração para eu fazer como se estivesse fazendo cocô e não sugar. (P4)

A enfermeira mandava eu fazer força para empurrar, eu fiz. Teve uma hora que parei. Ela disse: Mãe, faz força que está vindo a cabecinha. (P7)

A doutora pede para não gritar e fazer força para criança vir. (P9)

Quase todas as entrevistadas foram submetidas à amniotomia, durante o trabalho de parto. A realização da ruptura artificial das membranas amnióticas foi justificada pelos profissionais para fins de redução do tempo de trabalho de parto e favorecimento da descida do feto. Uma das puérperas mencionou desconhecimento sobre a real razão para a realização desse procedimento.

A médica tentou deixar romper sozinha, mas não vinha, aí a médica disse que ia romper a bolsa e eu disse que "tá". (P4)

A médica rompeu minha bolsa, mas não sei por quê. (P5)

Elas romperam, para que a criança baixasse e eu conseguisse ganhar normal, entendeu?(P6)

A médica rompeu minha bolsa. Ela disse que porque o colo estava lá em cima e ele precisava descer, eu tinha contração, tinha dilatação, mas ele não descia. Por isso, que estava demorando [...] (P8)

Eles [equipe de saúde] perguntaram para mim se eu queria ficar sofrendo as dores ou se eu queria romper a bolsa para não ser tão demorado, para não sentir tanta dor? Escolhi romper a bolsa para virem as dores mais rápido. (P9) 
As entrevistas também possibilitaram constatar a realização de pressão do fundo do útero durante o trabalho de parto, denominada de Manobra de Kristeller. Uma puérpera destacou que a conduta profissional, aliada aos comentários realizados na ocasião, lhe causaram sentimentos negativos.

Me senti muito ruim [quando realizaram a pressão do fundo do útero], é uma sensação muito ruim, porque a moça dizia que estava passando do tempo, que tinha que tirar, tirar, tirar, e empurrava com mão e tudo e não vinha. (P3)

A prática de episiotomia também emergiu nos relatos das entrevistadas. Percebe-se que elas não foram previamente informadas sobre o procedimento e pondera-se que este tenha sido realizado após anestesia local, já que elas não sentiram enquanto estava sendo realizado.

\section{[...] fizeram o corte, mas foi melhor que aíveio. (P4)}

Eu acho que o doutor fez, mas eu nem senti, não me falaram nada. (P7)

Fizeram o corte, mas eu nem senti. (P10)

De acordo com as participantes, o clampeamento do cordão umbilical foi realizado imediatamente após o nascimento. Nestes casos, foi possível observar a realização do procedimento de forma precoce.

Ela [recém-nascida] estava em cima de mim e eu não tinha nem visto, aí ele [médico] cortou [cordão umbilical] e eu nem senti. (P1)

Logo que nasceu cortaram o cordão. (P3)

[...] colocaram em cima de mim e cortaram [o cordão]. (P5)

Os achados demonstraram que os profissionais de saúde não aguardam a parada de pulsação do cordão. Além disso, tal conduta parece representar uma rotina no serviço. 


\section{Discussão}

Frente aos achados dessa pesquisa, é preciso reforçar que, conforme a Lei número 11.108, de 7 de abril de 2005, a parturiente tem o direito a ter um acompanhante durante todo o período de trabalho de parto, parto e pós-parto. A Lei também garante à gestante a sua livre escolha, podendo ser o pai do bebê, o/a parceiro/a atual, sua mãe, um/uma familiar ou um/uma amigo/a. Vale ressaltar que a Lei não pode ser desrespeitada pela instituição ou por qualquer membro da equipe de saúde, ${ }^{11}$ estando sujeita a denúncias em caso de descumprimento.

Contudo, nos relatos das puérperas, foi possível verificar que a presença do acompanhante só foi permitida antes e após o parto, contrariando os aspectos legais da legislação. Além disso, foi identificado que as entrevistadas puderam apenas usufruir de acompanhantes do sexo feminino, pois trata-se de recomendação do serviço, opondo-se novamente ao que propõe a Lei em pauta.

Nessa perspectiva, é importante destacar que o acompanhante no trabalho de parto e parto oferece diversos benefícios à mulher. ${ }^{12}$ Ele é capaz de fornecer segurança e tranquilidade e, com isso, auxiliar na redução da dor e da duração do trabalho de parto. Logo, a sua presença precisa ser mais estimulada pelos profissionais de saúde, uma vez que auxilia e incentiva durante o processo parturitivo, ${ }^{13}$ além de contribuir para a promoção de cuidado individualizado, considerando as subjetividades da parturiente. ${ }^{14}$ Para que tais efeitos sejam, de fato, usufruídos, a mulher precisa ter alguém da sua escolha, independente do gênero. Ainda, sua permanência deve acontecer do início ao fim do processo, independentemente do tempo que o trabalho de parto e parto durem.

Como práticas que se aproximaram da humanização do parto, constatou-se o uso de métodos não farmacológicos de alívio da dor durante o trabalho de parto. Nesse caso, procedimentos citados pelas puérperas foram a hidroterapia, a deambulação e os exercícios de relaxamento e agachamento. É recomendada a realização de estratégias não invasivas de alívio da dor no trabalho de parto, previamente à utilização de recursos farmacológicos. Dentre eles, destacam-se a oferta de imersão 
Práticas de atenção ao parto na experiência de puérperas: análise à luz da humanização | 14

em água, técnicas de massagem e de relaxamento, acupuntura e hipnose desenvolvidas por profissional habilitado, musicoterapia, entre outros. ${ }^{15}$

Autores reforçam que uma medida de conforto para muitas mulheres é a hidroterapia, especialmente durante o primeiro estágio do trabalho de parto. A água favorece o relaxamento e maior capacidade para sustentar as contrações, além de proporcionar uma experiência humanizada. ${ }^{16}$ Essa prática reduz o tempo de trabalho de parto, pois é favorecida pela gravidade, já que a mulher se mantém em posição vertical. Aliada a isso, tem-se a deambulação, que também contribui para a descida do bebê e consequente aumento da dilatação. ${ }^{17-18}$

A movimentação e adoção de posições confortáveis para a mulher precisam ser priorizadas. ${ }^{15}$ Contudo, no presente estudo, as entrevistadas alegaram que permaneceram mais restritas ao leito, principalmente, devido à infusão venosa.

Sobre esse aspecto, é importante salientar que a parturiente precisa ser estimulada a alternar as posições durante o trabalho de parto. Portanto, é preciso permitir que ela escolha outras posições, como a de cócoras, sentada, decúbito lateral, que contribuem para prevenção de lesões perineais, melhor comportamento biomecânico da pelve óssea e suas estruturas músculo ligamentares e, consequente, a descida fetal. ${ }^{19-20}$

O contato cutâneo direto e precoce entre mãe e filho e o apoio ao início da amamentação na primeira hora após o parto também emergiram como práticas profissionais desenvolvidas na atenção ao parto e nascimento. Com relação ao contato pele a pele, sabe-se que o recém-nascido pode permanecer sobre o abdome e/ou tórax da mãe após o clampeamento do cordão, utilizando o corpo da mãe como fonte de calor, certificando-se que o posicionamento da criança possibilite movimentos respiratórios efetivos. ${ }^{16}$

Sendo assim, é aconselhável estimular o contato pele a pele imediato entre mãe e bebê, logo após o nascimento. Os procedimentos de rotina como pesagem, medições e banho devem ser postergados a fim de evitar a separação entre mãe e filho, salvos os casos em que houver uma 
solicitação que parta da própria mulher e/ou quando realmente necessário. Na mesma direção, o estímulo ao aleitamento materno na primeira hora de vida é imprescindível, e apresenta inúmeros benefícios. $^{15}$

Um estudo realizado no Hospital Universitário credenciado com o título de Hospital Amigo da Criança, em Recife, justifica a realização da amamentação na primeira hora de vida por se tratar de estratégia de excelência, que contribui para a adaptação do recém-nascido em ambiente extrauterino. Ainda destaca que o início oportuno da amamentação é medida necessária para regular a glicemia e a temperatura da criança, assim como a sua condição cardiorrespiratória. ${ }^{21}$

Tratando-se das práticas que se distanciam da humanização, ${ }^{6}$ observou-se, nos achados do estudo em tela, a ocorrência de condutas profissionais que são classificadas na literatura como claramente prejudiciais ou ineficazes e que deveriam ser evitadas. ${ }^{15}$ Dentre essas, destacam-se a realização de enema e tricotomia, a infusão intravenosa de rotina no trabalho de parto e cateterização venosa profilática de rotina.

Identificou-se a realização de práticas com poucas evidências e que deveriam ser utilizadas com cautela, ${ }^{15}$ como é o caso da amniotomia precoce de rotina no primeiro estágio do trabalho de parto, a pressão do fundo durante o trabalho de parto e o clampeamento precoce do cordão umbilical. Por fim, ainda se constatou a realização de procedimentos frequentemente utilizados de modo inadequado, ${ }^{15}$ como a restrição hídrica e alimentar durante o trabalho de parto, estímulo para o puxo induzido antes que a mulher sinta o desejo involuntário, por exemplo.

No que se refere à tricotomia, já se reconhece que essa prática foi incorporada à rotina das instituições hospitalares mediante a justificativa de reduzir infecções e, no caso de evolução do trabalho de parto para a via vaginal, facilitar a sutura da episiotomia. Entretanto, atualmente, sabese que o risco de infecção não é reduzido com a realização de tricotomia. Ao contrário, o procedimento acarreta irritação, vermelhidão, ardor e coceira e, ainda, pode elevar a contaminação por doenças como o Vírus da Imunodeficiência Humana (HIV) e hepatites, tanto para o profissional 
Práticas de atenção ao parto na experiência de puérperas: análise à luz da humanização | 16

quanto para a mulher, representando, assim, em procedimento desnecessário e que só deveria ser realizado se solicitado pela mulher. ${ }^{22}$

A cateterização venosa profilática e a infusão intravenosa de ocitocina exógena de forma rotineira também foram evidenciadas nos depoimentos das participantes. Elas alegaram que estas práticas foram desenvolvidas pelos profissionais de saúde para reduzir o tempo de parto e o sofrimento causado pelas contrações. A utilização de ocitocina para estimulação do parto pode ser desfavorável, tanto para o recém-nascido quanto para a mulher. Está prática está associada ao aumento nas taxas de cesarianas, uso de analgesia peridural e febre materna intraparto e, portanto, a realização desse procedimento precisa ser avaliada com cautela. ${ }^{23}$

A ingesta hídrica, preferencialmente de soluções isotônicas, é uma prática que precisa ser estimulada. Parturientes que não estiverem sob efeito de drogas opioides ou que não possuírem risco de se submeter a uma anestesia geral podem ingerir dieta leve. ${ }^{15}$ Porém, no presente estudo, constatou-se que as mulheres atendidas no serviço em questão foram majoritariamente orientadas a permanecerem em jejum durante todo o processo de parturição.

As participantes também relataram a realização de exames vaginais repetidos ou frequentes por mais de um profissional de saúde. Os relatos demonstraram o constrangimento das mulheres, além da ausência de preocupação quanto à intimidade e individualidade dessas pacientes durante a realização destas avaliações. Um estudo desenvolvido em um hospital escola da capital do Rio Grande do Sul também identificou um número excessivo de exames vaginais em uma mesma paciente. Além disso, os autores destacaram que nenhuma das parturientes foi submetida à frequência de toques respeitando-se a recomendação a cada quatro horas, o que demonstrou avaliações demasiadas. ${ }^{22}$

Ademais, observou-se, no presente estudo, a orientação para que as participantes fizessem o esforço de puxo prolongado e dirigido (manobra de Valsalva), bem como a submissão destas à manobra de Kristeller, pelos profissionais de saúde. Nesse contexto, a literatura é enfática ao indicar 
que se deve estimular a parturiente a realizar puxos espontâneos durante o segundo período do trabalho de parto, evitando os puxos dirigidos. ${ }^{15}$ Além disso, essa manobra é considerada como procedimento desnecessário e danoso e que pode levar à lesão perineal, além de traumas psicológicos à mulher e físicos ao binômio. ${ }^{22}$

Ao permitir que a mulher vivencie o parto de maneira ativa, restitui-se o seu protagonismo nesse processo. Do contrário, quando os profissionais de saúde se dirigem a ela nomeando-a como “mãe” tal conduta pode ser considerada como uma prática de descompensação e responsabilização da mulher, que se distancia da humanização. ${ }^{6}$ Quando a parturiente não se comporta conforme o esperado pelos profissionais de saúde, ela pode ser considerada como descompensada e, nesses casos, é responsabilizada pela geração de estresse no ambiente. ${ }^{24}$

Nesse sentido, observou-se, nesta pesquisa, que uma das participantes relatou ter sido orientada a fazer força e que quando optou por outro comportamento, o profissional de saúde se dirigiu a ela como "mãe" e voltou a lhe orientar sobre o que deveria fazer. Além disso, outra participante também relatou ter sido orientada pelo profissional a não gritar e fazer força. Nas duas situações, é possível inferir que há a ideia de poder, infantilização e/ou restrição da imagem da mulher ao papel de mãe, destituindo-a das decisões sobre o seu comportamento e sobre o próprio corpo durante o processo de parto e nascimento. Portanto, essas condutas podem ser elencadas como práticas que se distanciam da humanização. ${ }^{6}$

Com isso, entende-se que os pressupostos da humanização do parto sinalizam a necessidade de uma nova postura dos profissionais de saúde. As relações entre profissional e usuário aparecem como questão cerne do cuidado, sendo necessário considerar a forma como os indivíduos são abordados e tratados, bem como a maneira como as suas dúvidas são esclarecidas e/ou como são ouvidas as suas demandas. ${ }^{25}$

Além disso, práticas profissionais que destituem o protagonismo feminino durante o processo de parturição se enquadram como violência obstétrica, a qual pode ser entendida como 
Práticas de atenção ao parto na experiência de puérperas: análise à luz da humanização | 18

uma forma particular e complexa de violência contra a mulher, costumando ser naturalizada nos sistemas de saúde e abrangendo a realização de procedimentos sem o consentimento da mulher, constituindo-se como tratamento desumanizado, abuso e desrespeitoso à parturiente. Esse tipo de violência também compreende todas as condutas que se distanciam da humanização do parto mencionadas na presente pesquisa e que podem ser configuradas como maus-tratos e práticas abusivas realizadas pelos profissionais de saúde. ${ }^{26-27}$

Na mesma direção que as manobras de Valsalva e de Kristeller, no estudo, a amniotomia foi desenvolvida com o intuito de reduzir o tempo do trabalho de parto. Contudo, torna-se essencial destacar que a amniotomia precoce, associada ou não ao uso de ocitocina sintética, não deve ser realizada de forma rotineira em mulheres que estejam apresentando boa evolução do trabalho de parto. A realização da ruptura artificial das membranas amnióticas é recomendada diante da suspeita de parada da progressão no primeiro estágio do trabalho de parto. Diante disso, quando indicado, deve-se explicar o procedimento à mulher e avisá-la de que tal conduta pode diminuir o período do trabalho de parto, mas, em contraponto, costuma acarretar no aumento da intensidade e da dor causada pelas contrações. ${ }^{15}$

No que se refere à episiotomia, essa é uma prática ainda muito difundida no contexto obstétrico, embora possa ser considerada uma forma de mutilação genital. ${ }^{28}$ Geralmente, está associada a variáveis como primiparidade, posição de litotomia durante a fase de expulsão, uso de analgesia epidural, parto instrumentado, uso de ocitocina durante o parto, indução do parto, e partos pós-termo. ${ }^{29}$ No entanto, está relacionada ao risco aumentado de laceração perineal de terceiro e quarto graus, infecção e hemorragia, incontinência urinária e fecal. ${ }^{30}$ Esses achados justificam o abandono dessa prática na assistência obstétrica atual.

Por fim, os relatos das participantes demonstraram o clampeamento e corte precoce do cordão umbilical, além da pressão do fundo uterino para a expulsão da placenta. Ambas as práticas representam condutas sem respaldo científico e, portanto, devem ser abolidas da assistência 
obstétrica. Desta forma, indicam-se alguns cuidados no terceiro período clínico do parto, como o clampeamento e corte tardio do cordão umbilical, preferencialmente, após a parada de sua pulsação, entre o $1^{\circ}$ e o $5^{\circ}$ minuto após o nascimento do bebê. ${ }^{15}$

Nos casos em que houver necessidade de realizar atendimento emergencial à mulher e/ou recém-nascido, o clampeamento e corte do cordão umbilical podem acontecer antes. O mesmo critério deve ser seguido para a dequitação da placenta, que deve ser fisiológica e respeitar o tempo e manifestações apresentadas pela mulher, a partir da identificação de algum sinal e/ou sintoma que evidencie que tal órgão está se descolando naturalmente do útero materno. ${ }^{15}$

Vale ponderar que essa pesquisa foi desenvolvida a partir da perspectiva de puérperas, podendo configurar-se como uma limitação do estudo, pois se reconhece a importância de estudos que também possam apontar a ótica dos profissionais de saúde atuantes no serviço que serviu de cenário para a coleta de dados. Com isso, vislumbra-se, por exemplo, um caminho para o desenvolvimento de pesquisas que permitam identificar os saberes dos profissionais de saúde sobre as práticas de atenção ao parto e nascimento, como também os entraves vivenciados para a implementação dessas.

\section{Conclusão}

Ao analisar as práticas profissionais desenvolvidas na atenção ao parto, na experiência de puérperas, à luz do aporte teórico de humanização, foi possível observar cada conduta e ação desenvolvidas. Com isso, foi possível identificar práticas consideradas prejudiciais e/ou ineficazes, como a realização de enema, tricotomia, infusão intravenosa de rotina no trabalho de parto e cateterização venosa profilática de rotina e manobras de Valsalva. Foi igualmente possível perceber os procedimentos que são desenvolvidos de forma inadequada, como os exames vaginais frequentes, restrição hídrica e alimentar e episiotomia. 
As práticas que se aproximaram da humanização do parto foram a presença do acompanhante, utilização de métodos de alívio da dor no trabalho de parto e o contato cutâneo precoce entre mãe e bebê, as quais emergiram timidamente nos depoimentos das participantes. Percebeu-se que, embora exista a possibilidade de a mulher usufruir da presença de um acompanhante durante seu trabalho de parto e parto, tal direito não se dá conforme a previsão legal. Outrossim, algumas mulheres foram estimuladas a utilizar técnicas não farmacológicas de alívio da dor, como hidroterapia, deambulação e exercícios de relaxamento e agachamento. O contato cutâneo precoce entre mãe e bebê, por sua vez, foi constatado no depoimento de apenas uma puérpera.

Os resultados deste estudo podem ser considerados como importantes contribuições para a prática no que tange o cuidado à mulher, recém-nascido e sua família durante o processo de nascimento. Tais achados poderão servir para subsidiar a reflexão dos profissionais de saúde quanto à necessidade de revisão e atualização das boas práticas de atenção ao parto, de forma a qualificar a assistência a esta parcela da população. No ensino, espera-se que o conhecimento produzido a partir desse estudo possa estimular a adoção de práticas baseadas em evidências científicas, contribuindo para a formação e atuação de profissionais críticos e alinhados com as atuais diretrizes de assistência obstétrica.

\section{Referências}

1. Victora CG, Aquino EM, Leal MC, Monteiro CA, Barros FC, Szwarcwald CL. Maternal and child health in Brazil: progress and challenges. Lancet. 2011;377(9780):1863-76. doi: 10.1016/S0140-6736(11)60138-4

2. Gottems LBD, Carvalho EMP, Guilhem D, Pires MRGM. Boas práticas no parto normal: análise da confiabilidade de um instrumento pelo Alfa de Cronbach. Rev Latinoam Enferm. 2018;26:e3000. doi: 10.1590/1518-8345.2234.3000

3. World Health Organization (WHO). Recommendations intrapartum care for a positive childbirth experience [Internet]. Geneva: World Health Organization; 2018 [cited 2019 Nov 15]. Available from: https://www.who.int/reproductivehealth/publications/intrapartum-care-guidelines/en/

4. Pereira SB, Diaz CMG, Backes MTS, Ferreira CLL, Backes DS. Boas práticas de atenção ao parto e ao nascimento na perspectiva de profissionais de saúde. Rev Bras Enferm. 2018;71(3):1393-9. doi: 10.1590/0034- 


\section{7-2016-0661}

5. Gomes SC, Teodoro LPP, Pinto AGA, Oliveira DR, Quirino GS, Pinheiro AKB. Renascimento do parto: reflexões sobre a medicalização da atenção obstétrica no Brasil. Rev Bras Enferm. 2018;71(5):2744-8. doi: 10.1590/0034-7167-2017-0564

6. Ministério da Saúde (BR). Política Nacional de Humanização. Brasília (DF): Ministério da Saúde; 2013.

7. Ministério Público de Pernambuco (MP-PE). Humanização do parto. Nasce o respeito: informações práticas sobre seus direitos. Recife: Procuradoria Geral de Justiça; 2015.

8. Amorim T, Araújo ACM, Guimarães EMP, Diniz SCF, Gandra HM, Cândido MCRM. Percepção de enfermeiras obstetras sobre o modelo e prática assistencial em maternidade filantrópica. Rev Enferm UFSM. 2019;9(e30):1-19. doi: 10.5902/2179769234868

9. Ministério da Saúde (BR). Instituto Sírio-Libanês de Ensino e Pesquisa. Protocolos da Atenção Básica: saúde das mulheres. Brasília (DF): Ministério da Saúde; 2016.

10. Minayo MCS. O desafio do conhecimento científico: pesquisa qualitativa em saúde. $14^{a}$ ed. São Paulo: Hucitec; 2014.

11. BRASIL. Ministério da Saúde. Lei no 11.108, de 7 de abril de 2005. Altera a Lei no 8.080, de 19 de setembro de 1990, para garantir às parturientes o direito à presença de acompanhante durante o trabalho de parto, parto e pós-parto imediato, no âmbito do Sistema Único de Saúde - SUS. Diário Oficial da União: seção 1, Brasília, DF, ano 142, n. 67, p. 1, 08 abr. 2005.

12. Gomes IEM, Padoin SMM, Langerdorf TF, Paula CC, Gomes CA, Ribeiro AC. Benefícios da presença do acompanhante no processo de parturição e nascimento: revisão integrativa. Rev Enferm UFSM. 2019;9(e61):118. doi: $10.5902 / 2179769234170$

13. Souza SRR, Gualda DMR. A experiência da mulher e de seu acompanhante no parto em uma maternidade pública. Texto Contexto Enferm. 2016;25(1):e4080014. doi: 10.1590/0104-0707201600004080014

14. Santos ALS, Oliveira ARS, Amorim T, Silva UL. O acompanhante no trabalho de parto sob a perspectiva da puérpera. Rev Enferm UFSM. 2015;5(3):531-40. doi: 10.5902/2179769217337

15. Ministério da Saúde (BR). Diretrizes nacionais de assistência ao parto normal: versão resumida [Internet]. Brasília (DF): Ministério da Saúde; 2017 [acesso em 2019 nov 15]. Disponível em: https://bvsms.saude.gov.br/bvs/publicacoes/diretrizes_nacionais_assistencia_parto_normal.pdf

16. Ministério da Saúde (BR). Cadernos HumanizaSUS: volume 4: humanização do parto e do nascimento. Brasília (DF): Ministério da Saúde [Internet]. 2014 [acesso em 2019 nov 15]. Disponível em: https://www.redehumanizasus.net/sites/default/files/caderno_humanizasus_v4_humanizacao_parto.pdf

17. Calvacanti ACV, Henrique AJ, Brasil CM, Gabrelloni MC, Barbieri M. Terapias complementares no trabalho de parto: ensaio clínico randomizado. Rev Gaúcha Enferm. 2019;40:e20190026. doi: 10.1590/1983- 
Práticas de atenção ao parto na experiência de puérperas: análise à luz da humanização | 22

1447.2019.20190026

18. Carvalho EMP, Amorim FF, Santana LA, Göttems LBD. Avaliação das boas práticas de atenção ao parto por profissionais dos hospitais públicos do Distrito Federal, Brasil. Ciênc Saúde Colet. 2019;24(6):2135-45. doi: 10.1590/1413-81232018246.08412019

19. Boaviagem A, Coutinho TA, Oliveira LGA, Moretti E. Comportamento biomecânico da pelve nas diferentes posturas adotadas durante o segundo período do trabalho de parto. Rev Eletrônica Estácio [Internet]. 2019 [acesso em 2020 maio 19];5(1). Disponível em: https://reer.emnuvens.com.br/reer/article/view/222/113

20. Torres M, Vinagre C, Godinho AB, Casal E, Pereira A. Evidência sobre a posição da grávida no segundo estádio do trabalho de parto. Acta Obstét Ginecol Port [Internet]. 2018 [acesso em 2020 maio 19];12(4):277-83. Disponível em: http://www.scielo.mec.pt/pdf/aogp/v12n4/v12n4a05.pdf

21. Silva JLP, Linhares FMP, Barros AA, Souza AG, Alves DS, Andrade PON. Fatores associados ao aleitamento materno na primeira hora de vida em um hospital amigo da criança. Texto Contexto Enferm. 2018;27(4):e4190017. doi: 10.1590/0104-07072018004190017

22. Lopes GC, Gonçalves AC, Gouveia HG, Armellini CJ. Attention to childbirth and delivery in a university hospital: comparison of practices developed after Network Stork. Rev Latinoam Enferm. 2019:27;e3139. doi: 10.1590/1518-8345.2643-3139

23. Hidalgo-Lopezosa P, Hidalgo-Maestre M, Rodríguez-Borrego MA. Labor stimulation with oxytocin: effects on obstetrical and neonatal outcomes. Rev Latinoam Enferm. 2016;24:e2744. doi: 10.1590/15188345.0765.2744

24. Tornquist CS. Paradoxos da humanização em uma maternidade no Brasil. Cad Saúde Pública. 2003;19(Supl 2):419-27. doi: 10.1590/S0102-311X2003000800023

25. Possati AB, Prates LA, Cremonese L, Scarton J, Alves CN, Ressel LB. Humanização do parto: significados e percepções de enfermeiras. Esc Anna Nery. 2017;21(4):e20160366. doi: 10.1590/2177-9465-ean-2016-0366

26. Sadler M, Santos MJ, Ruiz-Berdún D, Rojas GL, Skoko E, Gillen P, et al. Moving beyond disrespect and abuse: addressing the structural dimensions of obstetric violence. Reprod Health Matters. 2016;24(47):47-55. doi: 10.1016/j.rhm.2016.04.002

27. Jardim DMB, Modena CM. A violência obstétrica no cotidiano assistencial e suas características. Rev Latinoam Enferm. 2018;26:e3069. doi: 10.1590/1518-8345.2450.3069

28. Pompeu KC, Scarton J, Cremonese L, Flores RG, Landerhahl MC, Ressel LB. Prática da episiotomia no parto: desafios para a enfermagem. Rev Enferm Cent Oeste Min. 2017;7:e1142. doi: 10.19175/recom.v7i0.1142

29. Ballesteros-Meseguer C, Carrillo-García C, Meseguer-de-Pedro M, Canteras-Jordana M, Martínez-Roche ME. La episiotomía y su relación con distintas variables clínicas que influyen en su realización. Rev Latinoam Enferm. 2016;24:e2793. doi: 10.1590/1518-8345.0334.2686 
30. Sales JL, Quitete JB, Knupp VMAO, Martins MAR. Assistência ao parto em um hospital da baixada litorânea do Rio de Janeiro: desafios para um parto respeitoso. Rev Pesq Cuid Fundam. 2020;12:108-14. doi: 10.9789/2175-5361.rpcfo.v12.7092

Editora Científica Chefe: Cristiane Cardoso de Paula

Editora Associada: Graciela Dutra Sehnem

\section{Autor correspondente}

Lisie Alende Prates

E-mail: lisiealende@hotmail.com

Endereço: Rua Dr. Maia, 2160 apto 302 - Bairro Bela Vista - Uruguaiana/RS

CEP: 97501-768

\section{Contribuições de Autoria}

\section{1 - Pâmela da Rosa Gonzalez}

Concepção ou desenho do estudo/pesquisa, análise e interpretação dos dados, revisão final com participação crítica e intelectual no manuscrito.

\section{2 - Lisie Alende Prates}

Concepção ou desenho do estudo/pesquisa, análise e interpretação dos dados, revisão final com participação crítica e intelectual no manuscrito.

\section{3 - Joice Moreira Schmalfuss}

Análise e interpretação dos dados, revisão final com participação crítica e intelectual no manuscrito.

\section{4 - Jussara Mendes Lipinski}

Revisão final com participação crítica e intelectual no manuscrito.

\section{5 - Ana Paula de Lima Escobal}

Revisão final com participação crítica e intelectual no manuscrito.

\section{6 - Mari Luci Chalme da Silva}

Concepção ou desenho do estudo/pesquisa.

\section{Como citar este artigo}

Gonzalez PR, Prates LA, Schmalfuss JM, Lipinski JM, Escobal APL, Silva MLC. Práticas de atenção ao parto na experiência de puérperas: análise à luz da humanização. Rev. Enferm. UFSM. 2020 [Acesso em: Anos Mês Dia]; vol.11 e37: 1-23. DOI: https://doi.org/10.5902/2179769253146 